\title{
Detection and quantification of 14 Campylobacter species in pet dogs reveals an increase in species richness in feces of diarrheic animals
}

\author{
Bonnie Chaban', Musangu Ngeleka², Janet E Hill ${ }^{1 *}$
}

\begin{abstract}
Background: The genus Campylobacter includes many species, some of which are known human and animal pathogens. Even though studies have repeatedly identified domestic dogs as a risk factor for human campylobacteriosis, our understanding of Campylobacter ecology in this reservoir is limited. Work to date has focused primarily on a limited number of species using culture-based methods. To expand our understanding of Campylobacter ecology in dogs, a collection of fecal samples from 70 healthy and 65 diarrheic pet dogs were examined for the presence and levels of 14 Campylobacter species using quantitative PCR.

Results: It was found that $58 \%$ of healthy dogs and $97 \%$ of diarrheic dogs shed detectable levels of Campylobacter spp., with C. coli, C. concisus, C. fetus, C. gracilis, C. helveticus, C. jejuni, C. lari, C. mucosalis, C. showae, C. sputorum and $C$. upsaliensis levels significantly higher in the diarrheic population. Levels of individual Campylobacter species detected ranged from $10^{3}$ to $10^{8}$ organisms per gram of feces. In addition, many individual samples contained multiple species of Campylobacter, with healthy dogs carrying from 0-7 detectable species while diarrheic dogs carried from 0-12 detectable species.

Conclusions: These findings represent the largest number of Campylobacter species specifically tested for in animals and is the first report to determine quantifiable levels of Campylobacter being shed from dogs. This study demonstrates that domestic dogs can carry a wide range of Campylobacter species naturally and that there is a notable increase in species richness detectable in the diarrheic population. With several of the detected Campylobacter species known or emerging pathogens, these results are relevant to both ecological and public health discussions.
\end{abstract}

\section{Background}

Campylobacter is the most common bacterial cause of enteric disease worldwide [1], with an average of ten thousand Canadian and two million American cases reported annually [2,3]. Within the Campylobacter genus, C. jejuni, and its close relative C. coli, are reported as the most common cause of human acute bacterial enteritis. However, there is mounting evidence that other members of this genus, including C. upsaliensis, C. concisus, C. gracilis, C. rectus and C. showae, are under-appreciated for the part they play in enteritis, as well as other disease presentations [4-7]. With foodborne contamination the most recognized source for

\footnotetext{
* Correspondence: Janet.Hill@usask.ca

'Department of Veterinary Microbiology, University of Saskatchewan, Saskatoon, Canada
}

infections, ingestion of untreated water, raw milk, undercooked chicken and the cross-contamination of foods are recognized risk factors for acquiring Campylobacter [8-11]. In addition, many natural animal reservoirs for Campylobacter have been recognized, which include chicken and other poultry, wild birds, pigs, dogs, cats, sheep and cows [12]. Studies from the United States, Sweden and Australia all identify ownership of a pet dog as a risk factor for Campylobacter infections, especially among infants and small children [8-10]. Despite this fact, our knowledge of Campylobacter ecology in dogs is quite limited.

Research carried out in Europe and Asia has begun to address this question with various culture-based studies. Researchers from Taiwan, Finland, Sweden, Demark and the Netherlands have examined various dog populations 
and have been able to culture C. jejuni, C. coli, C. upsaliensis, C. helveticus, C. lari and other Campylobacter spp. from canine fecal samples using various growth conditions and media [13-17]. Reported carriage rates of Campylobacter spp. in domestic dogs ranged from 2.7\% to $100 \%$ of dogs tested $[13,16]$, with some studies reporting isolation of multiple species of Campylobacter from a single dog $[15,17]$.

A major influence on our understanding of Campylobacter ecology in dogs has been our reliance on culturebased methods. Various selective media have been used for Campylobacter isolation [18], with most relying on a cocktail of antibiotics in a rich basal medium to selectively isolate Campylobacter. However, it has been recognized that Campylobacter species other than C. coli, C. jejuni, and C. lari are often sensitive to the antibiotics in these media [19]. Filter-based methods, in combination with nonselective media, have been shown to result in the isolation of a greater diversity of Campylobacter species [20], but these approaches are more labour-intensive, less selective and prone to overgrowth of fecal contaminants [19]. As our understanding of campylobacters, both pathogenic and non-pathogenic, expands beyond $C$. jejuni and C. coli, so must our detection methods.

The goal of this study was to take a culture-independent approach to the profiling of Campylobacter species in domestic pet dogs in an effort to evaluate this zoonotic reservoir and describe changes in fecal Campylobacter populations associated with diarrhea. Established species-specific quantitative PCR (qPCR) assays targeting the $60 \mathrm{kDa}$ chaperonin (cpn60) gene of C. coli, C. concisus, C. curvus, C. fetus, C. gracilis, C. helveticus, C. hyointestinalis, C. jejuni, C. lari, C. mucosalis, C. rectus, C. showae, C. sputorum, and C. upsaliensis [21] were used to determine the Campylobacter profiles of 70 healthy dogs and 65 dogs with diarrhea. This study represents the largest culture-independent, quantitative investigation of Campylobacter in pet dogs conducted to date and is one of only a few studies to focus on North American animals.

\section{Results}

\section{Campylobacter profiles from healthy and diarrheic dog fecal samples}

Total bacterial DNA was extracted from the feces of 70 healthy dogs (from 52 households) and 65 dogs with diarrhea (from 60 households) (Additional file 1: Table S1) and tested for the presence of 14 Campylobacter species. Each sample was tested for an individual species in four reactions (duplicate reactions within an assay and each assay run twice). If a sample did not yield three or four detectable test values (above the assay cutoff of $10^{3}$ organisms/g of feces [21]), the sample was defined as undetectable for that test. In the cases where only one or two of the four test reactions generated a detectable value, these values where at the bottom limit of assay's detection capability. Although we acknowledge that this may lead to a slight underestimation of Campylobacter DNA present, these samples were deemed too close to the lower assay detection limit to be confidently called as a positive sample for that test. In all other cases, positive values for a sample were within one log value of each other and all four reactions were averaged to generate the detected level of an individual Campylobacter species within that sample.

Figure 1 summarizes the levels of Campylobacter detected in each sample for each species tested. Campylobacter species were detected in 56\% (39/70) of healthy and $97 \%(63 / 65)$ of diarrheic dog feces. In a species by species comparison, significantly more diarrheic samples were positive for 11 of the 14 species assayed, with only C. curvus, C. hyointestinalis and C. rectus detection rates remaining constant between populations (Table 1). C. upsaliensis, commonly reported as the predominant Campylobacter species recovered from dogs [14-17], was also the predominant species detected in this study, with $43 \%(30 / 70)$ of healthy dogs and $85 \%(55 / 65)$ of diarrheic dogs shedding detectable levels. As well, human pathogens $C$. jejuni and C. showae could be detected at a low prevalence in the healthy dog population $(7 \%(5 / 70)$ and $6 \%(4 / 70)$, respectively) and at a significantly higher prevalence in the diarrheic population (46\% (30/65) and 28\% (18/65), respectively). Also of note, C. coli was undetectable in the healthy dog population (0/70) but detectable in $25 \%(16 / 65)$ of dogs with diarrhea. Other species detected only in the diarrheic dog population were C. concisus, C. gracilis, C. lari and C. mucosalis.

Beyond a strictly present/absent detection of each species, the qPCR assays used in this study generate quantitative values for the number of target organisms detected per reaction [21,22]. From both the healthy and diarrheic dog populations, individual Campylobacter species detected in feces ranged from $10^{3}$ organisms $/ g$ (the lower detection limit of the assays) to $10^{8}$ organisms/g (Figure 1). Within the healthy population, only C. fetus and C. upsaliensis were detected at levels of $10^{6}$ organisms/g of feces or higher. This is in contrast to the diarrheic population, where C. concisus, C. fetus, C. helveticus, C. jejuni, C. lari, C. showae and C. upsaliensis were detectable in samples at $10^{6}$ organisms/g of feces or higher. Interestingly, despite the fact that more species were present at higher levels in the diarrheic population, the maximum level of any individual Campylobacter species detected from a sample was not more than $10^{8}$ organisms/g of feces in either population (Figure 1). 


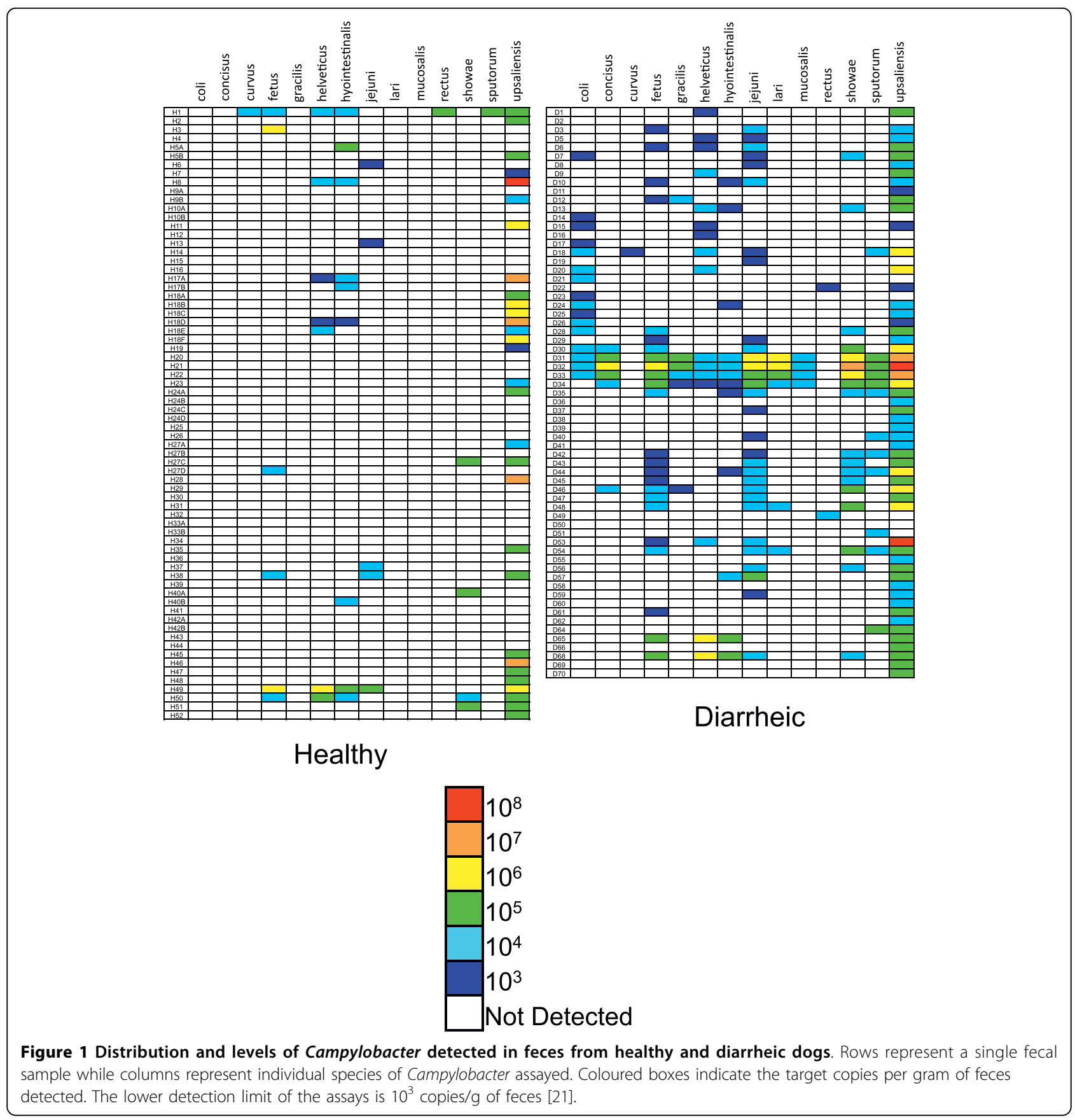

In addition to an increase in the number of samples positive for any of the 14 Campylobacter species tested for, the diarrheic dog samples also had a higher species richness (Figures $1 \& 2$ ). Figure 2 summarizes the number of different Campylobacter species detected from individual samples. For healthy dogs, $42 \%$ (31/70) of samples had no detectable Campylobacter, 41\% (29/70) had a single species detectable and only $14 \%(10 / 70)$ had two or more species detectable. This compares to $3 \%(2 / 65)$ of diarrheic samples that had no detectable Campylobacter,
$31 \%(20 / 65)$ had a single species detectable and $66 \%$ $(43 / 65)$ had two or more species. Remarkably, three of the diarrheic samples tested had 12 different species of Campylobacter present, with individual species ranging from $10^{4}$ to $10^{8}$ organisms/g (Figure 1 ).

\section{Total bacteria levels in dog fecal samples}

To determine if the difference in Campylobacter profiles of healthy and diarrheic dogs could be accounted for by an overall difference in fecal bacteria shedding, the total 
Table 1 Numbers of healthy and diarrheic dog fecal samples positive for each species of Campylobacter tested $^{\mathrm{a}}$

\begin{tabular}{lcc}
\hline & \multicolumn{2}{c}{ Number of Positive samples } \\
\cline { 2 - 3 } & Healthy (/70) & Diarrheic (/65) \\
\hline C. coli & 0 & $16^{* *}$ \\
C. concisus & 0 & $6^{*}$ \\
C. curvus & 1 & 1 \\
C. fetus & 6 & $24^{* *}$ \\
C. gracilis & 0 & $6^{*}$ \\
C. helveticus & 7 & $16^{*}$ \\
C. hyointestinalis & 9 & 12 \\
C. jejuni & 5 & $30^{* *}$ \\
C. lari & 0 & $6^{*}$ \\
C. mucosalis & 0 & $4^{*}$ \\
C. rectus & 1 & 2 \\
C. showae & 4 & $18^{* *}$ \\
C. sputorum & 1 & $12^{* *}$ \\
C. upsaliensis & 30 & $55^{* *}$ \\
\hline
\end{tabular}

${ }^{a}$ Statistically significant differences based on an independent t-test or Mann Whitney $\mathrm{U}$ test are indicated with an asterisk $(\mathrm{p}<0.05)$ or double asterisk $(\mathrm{p}$ $<0.002$ )

amount of detectable bacterial DNA per gram of feces was measured from each group. Twenty samples from each population were randomly selected and GPCR was performed to determine the total $16 \mathrm{~S}$ rRNA gene copies detectable in the fecal DNA extracts. We found that both healthy and diarrheic fecal populations had approximately $10^{9}$ copies/g of the $16 \mathrm{~S}$ rRNA gene detectable (Figure 3 ), with no statistically significant difference between the populations $(p=0.818)$. This indicates that detectable bacterial levels being shed in dog feces are consistent, regardless of the animals' clinical state or the etiology of the diarrhea. Therefore, the increase in detectable Campylobacter shedding during diarrhea appears to be the result of an increase in the proportion of Campylobacter present compared to the total bacterial population.

\section{Discussion}

Campylobacter species could readily be detected in feces from both the healthy and diarrheic dogs (Figure 1). From a public health perspective, several findings are of note. C. upsaliensis, which was the predominant species detected in this study, has been reported, second only to C. jejuni, as the most frequently isolated cause of campylobacteriosis in some US settings [5]. As well, many of the Campylobacter species examined, including known or emerging human pathogens, were detectable in both the healthy and diarrheic dog populations, with most species found at significantly higher levels in the diarrheic population (Table 1). This becomes increasingly relevant when the level of organisms detected is considered. Figure 1 highlights that in both dog populations, Campylobacter levels reaching $10^{8}$ organisms/g of feces could be detected. With reports that the human infectious dose for campylobacteriosis by $C$. jejuni can be as low as $8 \times 10^{2}$ organisms ingested [23], the possibility of accidental exposure to infectious levels of

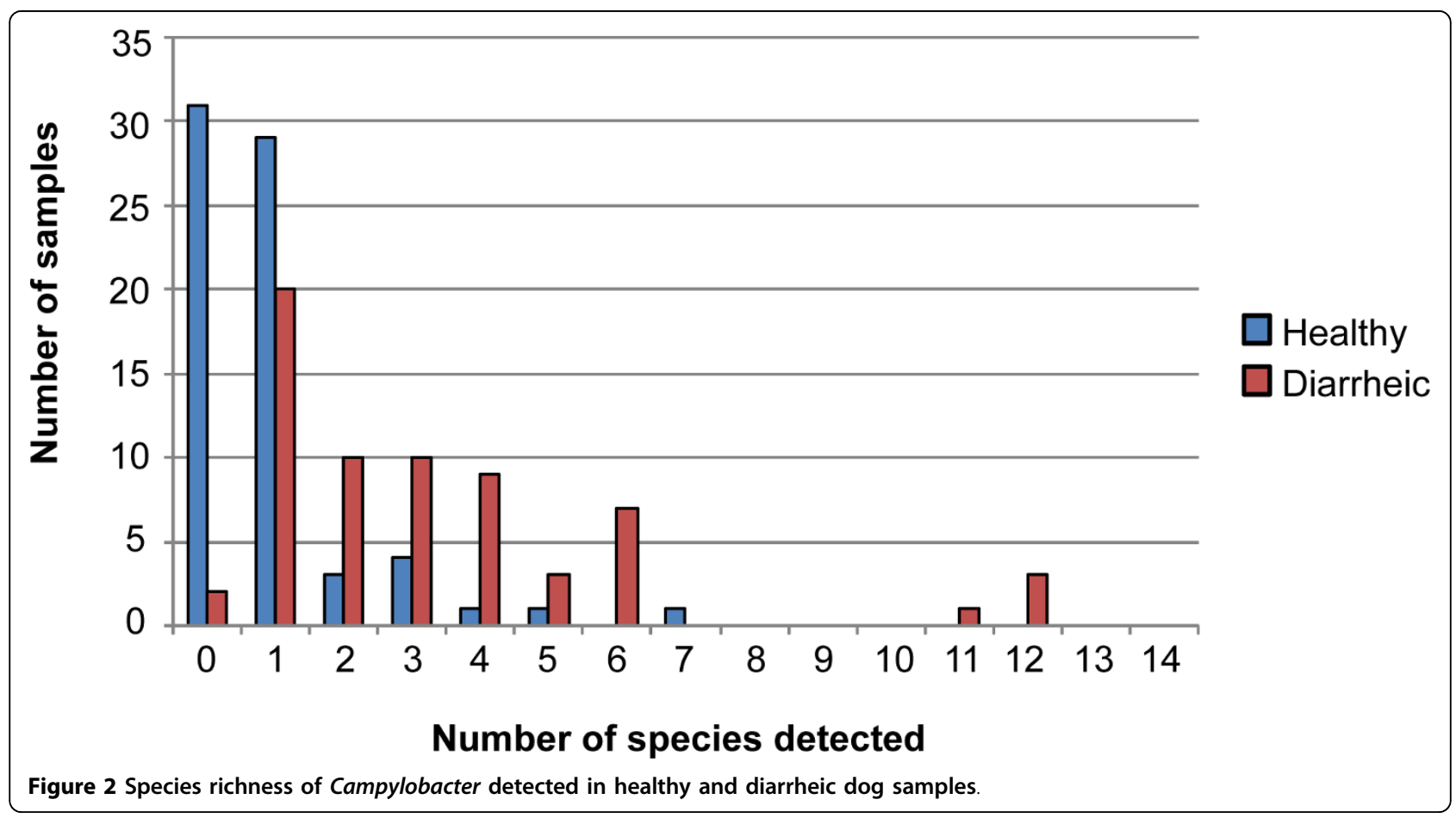




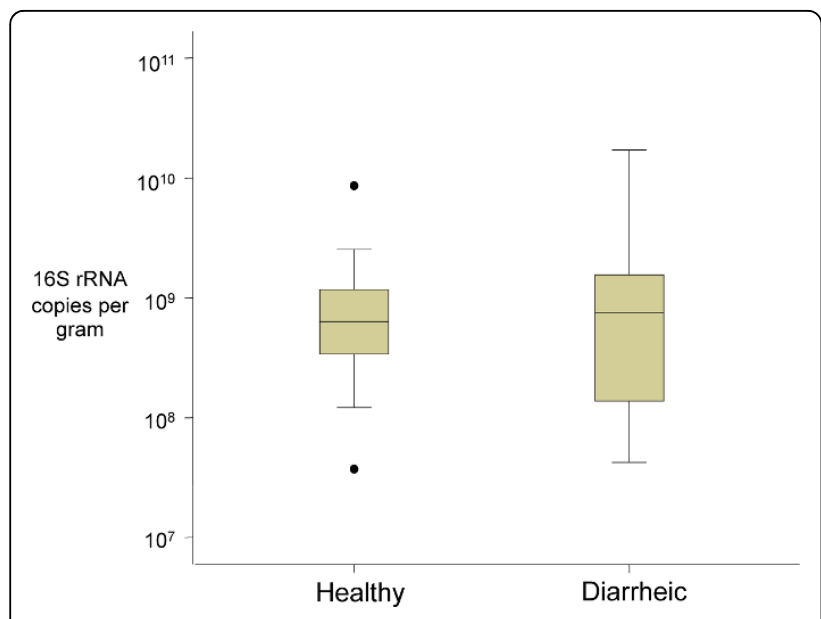

Figure 3 Total bacterial 16S rRNA gene copies detected per gram of healthy and diarrheic dog feces $(n=20$ for each population). Box plots show the $25^{\text {th }}$ to $75^{\text {th }}$ percentile range of the data within the box, with the median indicated with a line in the box. The whiskers represent the remaining quartile ranges, with outliers indicated as dots.

Campylobacter from pet dogs in a household is within the realm of possibility. Taken together, our results support the findings of previous groups indicating pet dogs as a risk factor for campylobacteriosis [8-10].

From a Campylobacter ecology perspective, an important finding from this data is the species richness of Campylobacter detected, particularly in the diarrheic samples. The diarrheic dog samples examined in this study came from clinical submissions where the major clinical sign was persistent diarrhea. In the veterinary context, samples from acute cases (often caused by dietary indiscretion; i.e. eating garbage) would be submitted rarely since the diarrhea episode would resolve in a short time. The etiology of the diarrhea was not considered in our sample selection, although in many cases, intestinal bacterial overgrowth associated with increased numbers of Clostridium perfringens was suspected. This suggests that the apparent enrichment of Campylobacter populations may be related to environmental changes consistent with the physiological condition of diarrhea (which may include increased stool volume and weight, increased defecation frequency and loose stools), rather than any particular pathogen or disorder. This is consistent with reports of an increase in $C$. coli numbers in pigs suffering from swine dysentery caused by Brachyspira hyodysenteriae, where the reason for that Campylobacter increase was unclear [24]. It is possible that the healthy dogs had similar species richness, but the majority of species were present at a level below our tests' detection limits. However, the maximum levels of organisms detected were similar in the healthy and diarrheic samples $\left(\sim 10^{8}\right.$ organisms/g, Figure 1$)$, suggesting that enrichment of Campylobacter species in the dogs with diarrhea was not uniform and that the maximum abundance of Campylobacter is limited in some way. Regardless of the mechanism responsible, it appears that something about the physiological state of diarrhea is favourable for Campylobacter species within the context of the intestinal microbiota.

\section{Conclusions}

Pets are members of the North American family, with $37 \%$ of American and 33\% of Canadian households containing pet dogs $[25,26]$. As our understanding of Campylobacter pathogenicity increases, so must our understanding of its reservoirs and ecology. Domestic dogs are recognized as a risk factor for campylobacteriosis and this report reinforces those findings. We found human pathogens like C. jejuni, C. coli, C. upsaliensis, C. gracilis, C. concisus and C. showae in dog feces, with significantly higher levels present in dogs with diarrhea. As well, we see that disturbances to the intestinal microbiota related to diarrhea have an effect on Campylobacter ecology. How and why this is the case, as well as how this change in Campylobacter distribution relates to the overall intestinal community, are areas of future investigation.

\section{Methods}

\section{Sample Collection}

Fecal samples from healthy dogs were submitted for analysis by pet owners from the Saskatoon, SK, Canada metropolitan area (population 250,000) (Additional file 1: Table S1). All dogs were considered healthy by their owners and had not received antibiotic therapy for at least six months prior to sample collection. Samples were collected in accordance with the University of Saskatchewan Animal Research Ethics Board (protocol \#20090054). Fecal specimens from dogs suffering from diarrhea (of any etiology) were obtained from samples submitted to Prairie Diagnostic Services Inc., Saskatoon, SK for routine bacteriology and/or parasitology testing (Additional file 1: Table S1). All samples were stored at $-80^{\circ} \mathrm{C}$ until processed for PCR analysis.

\section{DNA Extraction}

Total bacterial DNA was extracted from fecal samples using the QIAamp DNA stool kit (Qiagen), as per manufacturer's instructions. Final DNA samples were diluted 1:10 with sterile water before analysis. This was done to improve the overall sensitivity of the assays used, which are known to be affected by PCR inhibitors carried through fecal DNA extractions [21].

\section{Quantitative PCR (qPCR)}

The detection and quantification of the 14 species of Campylobacter reported was done using assays targeting 
the cpn60 gene using the primer sets and PCR conditions described in [21]. The lower detection limit of these assays is $10^{3}$ copies/g of feces [21]. Total bacterial DNA levels were measured by quantification of the $16 \mathrm{~S}$ rRNA gene, using the primer set SRV3-1/SRV3-2 (with an annealing temperature of $62^{\circ} \mathrm{C}$ ) described in [27]. All assay reaction mixtures consisted of $1 \times \mathrm{iQ}$ SYBR green supermix (Bio-Rad), $400 \mathrm{nmol} / \mathrm{L}$ concentrations of each of the appropriate primers, and $2 \mu \mathrm{L}$ of template DNA in a final volume of $25 \mu \mathrm{L}$. An iCycler or MyiQ thermocycler (Bio-Rad) was used for all reactions with the following program: $95^{\circ} \mathrm{C}$ for $3 \mathrm{~min}$, followed by 40 cycles of $15 \mathrm{~s}$ at $95^{\circ} \mathrm{C}, 15 \mathrm{~s}$ at the appropriate annealing temperature, and $15 \mathrm{~s}$ at $72^{\circ} \mathrm{C}$. A final melt at $95^{\circ} \mathrm{C}$ for $1 \mathrm{~min}$ was done prior to a dissociation curve analysis $\left(55^{\circ} \mathrm{C}\right.$ to $95^{\circ} \mathrm{C}$ in $0.5^{\circ} \mathrm{C}$ steps for $10 \mathrm{~s}$ increments). Fluorescence signals were measured every cycle at the end of the annealing step and continuously during the dissociation curve analysis. The resulting data were analyzed using iQ5 optical system software (Bio-Rad). All reactions were performed in duplicate (within the assay) and each assay was performed twice, resulting in four evaluations of each sample.

\section{Statistical Analysis}

All statistical analyses were done using SPSS software (SPSS Inc., Chicago, IL, USA). Campylobacter and total bacterial count data was analyzed for significance using the independent sample $\mathrm{t}$-test or the Mann-Whitney $\mathrm{U}$ test, as appropriate.

Additional file 1: Table S1. Additional information about the dogs from which samples were collected, including breed, age, diet and symptoms (where applicable). Relevant information about the dogs used in this study, with the healthy dog information provided by their owners at time of sample collection and the diarrheic dog information taken from case file information when sample was submitted for testing at Prairie Diagnostic Services.

Click here for file

[http://www.biomedcentral.com/content/supplementary/1471-2180-1073-S1.DOC]

\section{Acknowledgements \\ The authors gratefully thank the staff at Prairie Diagnostic Services, Central Animal Veterinary Hospital and the dog owners of the city of Saskatoon, SK for their invaluable assistance in sample collection, as well as Champika Fernando for assistance with statistical analyses. This study was supported by a Saskatchewan Health Research Foundation (SHRF) Establishment grant to JEH and a SHRF Postdoctoral Fellowship to BC. \\ Author details \\ 'Department of Veterinary Microbiology, University of Saskatchewan, Saskatoon, Canada. ${ }^{2}$ Prairie Diagnostic Services Inc, University of Saskatchewan, Saskatoon, Canada.}

\section{Authors' contributions}

BC participated in sample collection, carried out all sample preparation and testing, participated in statistical analysis and drafted the manuscript. MN coordinated sample collection and participated in the design of the study and analysis. JEH conceived of the study, and participated in its design and coordination and helped to draft the manuscript. All authors read and approved the final manuscript.

Received: 7 January 2010 Accepted: 10 March 2010

Published: 10 March 2010

\section{References}

1. WHO: Fact Sheet No. 255: Campylobacter. Geneva: (WHO) 2000.

2. Bowman C, Flint J, Pollari F: Canadian integrated surveillance report: Salmonella, Campylobacter, pathogenic E. coli and Shigella, from 1996 to 1999. Canada Communicable Dis Report 2003, 29(Suppl 1(1)), i-vi, 1-32..

3. Samuel MC, Vugia DJ, Shallow S, Marcus R, Segler S, McGivern T, Kassenborg H, Reilly K, Kennedy M, Angulo F, et al: Epidemiology of sporadic Campylobacter infection in the United States and declining trend in incidence, FoodNet 1996-1999. Clin Infect Dis 2004, 38(Suppl 3): S165-174.

4. Newell DG: Campylobacter concisus: an emerging pathogen? Eur J Gastroen Hepat 2005, 17(10):1013-1014.

5. Labarca JA, Sturgeon J, Borenstein L, Salem N, Harvey SM, Lehnkering E, Reporter R, Mascola L: Campylobacter upsaliensis: Another pathogen for consideration in the United States. Clin Infect Dis 2002, 34(11):E59-60.

6. Siqueira JF Jr, Rôças IN: Campylobacter gracilis and Campylobacter rectus in primary endodontic infections. Int Endod J 2003, 36(3):174-180.

7. de Vries JJ, Arents NL, Manson WL: Campylobacter species isolated from extra-oro-intestinal abscesses: a report of four cases and literature review. Eur J Clin Microbiol Infect Dis 2008, 27(11):1119-1123.

8. Fullerton KE, Ingram LA, Jones TF, Anderson BJ, McCarthy PV, Hurd S, Shiferaw B, Vugia D, Haubert N, Hayes T, et al: Sporadic Campylobacter infection in infants: a population-based surveillance case-control study. Pediatr Infect Dis J 2007, 26(1):19-24.

9. Tenkate TD, Stafford RJ: Risk factors for campylobacter infection in infants and young children: a matched case-control study. Epidemiol Infect 2001, 127(3):399-404.

10. Carrique-Mas J, Andersson Y, Hjertqvist M, Svensson A, Torner A, Giesecke J: Risk factors for domestic sporadic campylobacteriosis among young children in Sweden. Scand J Infect Dis 2005, 37(2):101-110.

11. Marcus R: New information about pediatric foodborne infections: the view from FoodNet. Curr Opin Pediatr 2008, 20(1):79-84.

12. Skirrow MB: Epidemiology of Campylobacter enteritis. Int J Food Microbiol 1991, 12(1):9-16.

13. Tsai HJ, Huang HC, Lin CM, Lien YY, Chou CH: Salmonellae and campylobacters in household and stray dogs in northern Taiwan. Vet Res Commun 2007, 31(8):931-939.

14. Rossi M, Hänninen ML, Revez J, Hannula M, Zanoni RG: Occurrence and species level diagnostics of Campylobacter spp., enteric Helicobacter spp. and Anaerobiospirillum spp. in healthy and diarrheic dogs and cats. Vet Microbiol 2008, 129(3-4):304-314.

15. Engvall EO, Brandstrom B, Andersson L, Baverud V, Trowald-Wigh G, Englund L: Isolation and identification of thermophilic Campylobacter species in faecal samples from Swedish dogs. Scand J Infect Dis 2003, 35(10):713-718.

16. Hald B, Pedersen K, Waino M, Jorgensen JC, Madsen M: Longitudinal study of the excretion patterns of thermophilic Campylobacter spp. in young pet dogs in Denmark. J Clin Microbiol 2004, 42(5):2003-2012.

17. Koene MG, Houwers DJ, Dijkstra JR, Duim B, Wagenaar JA: Simultaneous presence of multiple Campylobacter species in dogs. J Clin Microbiol 2004, 42(2):819-821.

18. Corry JE, Post DE, Colin P, Laisney MJ: Culture media for the isolation of campylobacters. Int J Food Microbiol 1995, 26(1):43-76.

19. Engberg J, On SL, Harrington CS, Gerner-Smidt P: Prevalence of Campylobacter, Arcobacter, Helicobacter, and Sutterella spp. in human fecal samples as estimated by a reevaluation of isolation methods for Campylobacters. J Clin Microbiol 2000, 38(1):286-291.

20. Le Roux E, Lastovica AJ: The Cape Town Protocol: how to isolate the most campylobacters for your dollar, pound, franc, yen, etc. Proceedings of the 9th International Workshop on Campylobacter, Helicobacter and Related Organisms: September 15 - 19, 1997 1998; Cape Town, South Africa Institute of Child Health, Cape Town, South Africa 1998, 30-33. 
21. Chaban B, Musil KM, Himsworth CG, Hill JE: Development of cpn60-based real-time quantitative PCR assays for the detection of 14 Campylobacter species and application to screening of canine fecal samples. Appl Environ Microbiol 2009, 75(10):3055-3061.

22. Hill JE, Penny SL, Crowell KG, Goh SH, Hemmingsen SM: cpnDB: a chaperonin sequence database. Genome Res 2004, 14(8):1669-1675.

23. Black RE, Levine MM, Clements ML, Hughes TP, Blaser MJ: Experimental Campylobacter jejuni infection in humans. J Infect Dis 1988, 157(3):472-479.

24. Quin PJ, Carter ME, Markey BK, Carter GR: Campylobacter species. Clinical Veterinary Microbiology London: Wolfe Publisher, Year Book Europe LimitedQuin PJ, Carter ME, Markey BK, Carter GR 1994, 268-272.

25. American Veterinary Medical Association: U.S. Pet Ownership \& Demographics Sourcebook. 2007.

26. Ipsos Reid: Paws and Claws, a syndicated study on Canadian Pet Ownership. 2001.

27. Lee $D H$, Zo YG, Kim SJ: Nonradioactive method to study genetic profiles of natural bacterial communities by PCR-single-strand-conformation polymorphism. Appl Environ Microbiol 1996, 62(9):3112-3120.

doi:10.1186/1471-2180-10-73

Cite this article as: Chaban et al: Detection and quantification of 14 Campylobacter species in pet dogs reveals an increase in species richness in feces of diarrheic animals. BMC Microbiology 2010 10:73.

\section{Submit your next manuscript to BioMed Central} and take full advantage of:

- Convenient online submission

- Thorough peer review

- No space constraints or color figure charges

- Immediate publication on acceptance

- Inclusion in PubMed, CAS, Scopus and Google Scholar

- Research which is freely available for redistribution

Submit your manuscript at www.biomedcentral.com/submit 